\title{
WestVirginiaUniversity
}

THE RESEARCH REPOSITORY @ WVU

Graduate Theses, Dissertations, and Problem Reports

2018

\section{Caregiver Selection of Treatments for Their Child with Autism}

Amy Kurowski-Burt

West Virginia University, alburt@hsc.wvu.edu

Follow this and additional works at: https://researchrepository.wvu.edu/etd

Part of the Occupational Therapy Commons

\section{Recommended Citation}

Kurowski-Burt, Amy, "Caregiver Selection of Treatments for Their Child with Autism" (2018). Graduate Theses, Dissertations, and Problem Reports. 4057.

https://researchrepository.wvu.edu/etd/4057

This Dissertation is protected by copyright and/or related rights. It has been brought to you by the The Research Repository @ WVU with permission from the rights-holder(s). You are free to use this Dissertation in any way that is permitted by the copyright and related rights legislation that applies to your use. For other uses you must obtain permission from the rights-holder(s) directly, unless additional rights are indicated by a Creative Commons license in the record and/ or on the work itself. This Dissertation has been accepted for inclusion in WVU Graduate Theses, Dissertations, and Problem Reports collection by an authorized administrator of The Research Repository @ WVU.

For more information, please contact researchrepository@mail.wvu.edu. 


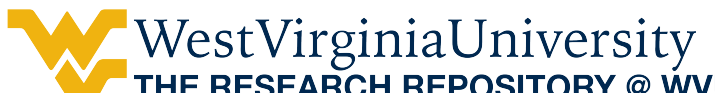

THE RESEARCH REPOSITORY @ WVU

Graduate Theses, Dissertations, and Problem Reports

2019

Caregiver Selection of Treatments for Their Child with Autism

Amy Kurowski-Burt

Follow this and additional works at: https://researchrepository.wvu.edu/etd

Part of the Occupational Therapy Commons 
Caregiver Selection of Treatments for Their Child with Autism

Amy Kurowski-Burt

Dissertation submitted to the College of Education and Human Services at West Virginia University

In partial fulfillment of the requirements for the degree of Ed.D. in Educational Psychology

Reagan Curtis, Ph.D., Chair

M. Cecil Smith, Ph.D.

Karen Rambo-Hernandez, Ph.D.

Mary Beth Mandich, Ph.D.

Department of Learning Sciences and Human Development

Morgantown, West Virginia

2019

Keywords: autism, survey, caregivers, treatments

Copyright 2019 Amy Kurowski-Burt 


\section{ABSTRACT \\ Caregiver Selection of Treatments for Their Child with Autism}

Amy Kurowski-Burt

This project was completed to understand what treatments caregivers are selecting for their child with autism and why treatments were selected and discontinued. Caregivers of children with autism participated in a mixed methods study. An online survey was completed $(\mathrm{N}=127)$ to identify treatments used for their child. Interviews were completed ( $n=14)$ to understand why treatments were selected and discontinued. Selection of medical, dietary, therapeutic, complimentary/ alternative medicine, community-based, behavioral, and educational treatments were mostly influenced by recommendations of others. Caregivers reported discontinuing because relationships and professionalism were lacking between provider and family. Providers must consider all the variables that influence caregivers' intervention selection to ensure caregiver follow through to encourage change. 
TABLE OF CONTENTS

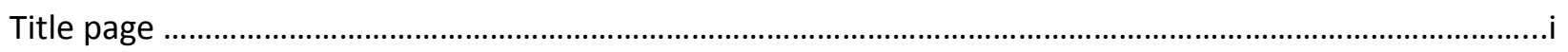

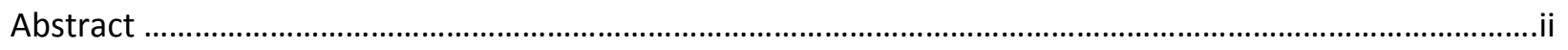

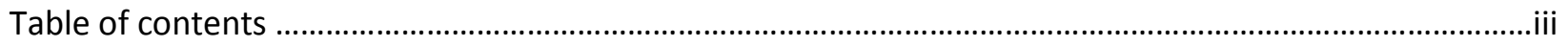

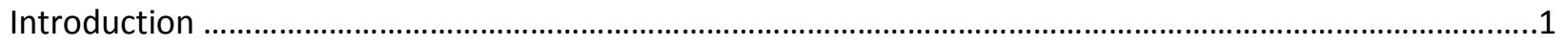

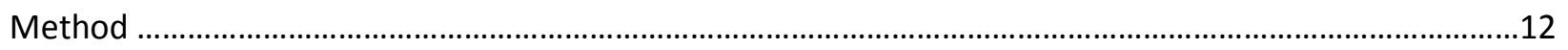

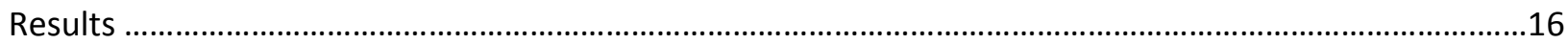

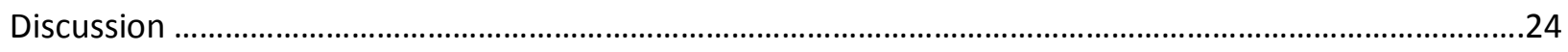

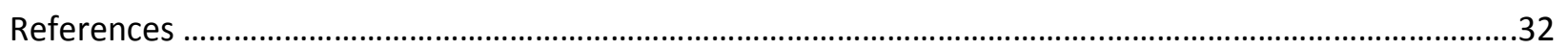

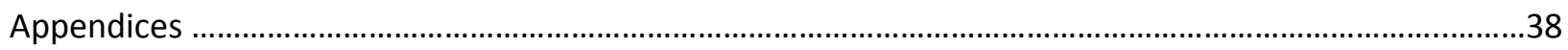




\section{Caregiver Selection of Treatments for Their Child with Autism}

Autism Spectrum Disorder (ASD), or autism, is a pervasive neurodevelopmental disorder that affects approximately 1 in 68 children and which has no known cure (Centers for Disease Control [CDC], 2017). ASD is prevalent in all demographics for age, race, and region. Males are four times more likely to have an ASD than females. As per the DSM-V diagnostic criteria, a child with impairments in social interaction, communication, and behavior will be diagnosed with autism spectrum disorder. Severity must also be identified by assigning a level of 1-3, with level 3 indicative of marked deficits in the three areas listed previously (Autism Speaks, 2018). This is a spectrum disorder due to the variability in symptoms from one person to another. Prior to the DSM-V, children were identified with autistic disorder, Asperger syndrome, or pervasive developmental disorder- not otherwise specified (PDD-NOS, American Occupational Therapy Association [AOTA], 2018). For purposes of this research study, the prior diagnostic criteria labels will be used at times when discussing the diagnosis and treatment because most of the literature was written in accordance with the DSM-IV.

Due to the impact on child functioning and socialization, caregivers may seek radical treatments more so than with other disabilities or diagnoses. With minimal outcomes observed or noted by the caregivers, treatments may be frequently discontinued and added. Professionals who assist their clients in finding treatments to help with autism should focus on patient and family goals. Recommended treatments should be reasonable given the available resources of the family (Lancaster, 2005; Mire, Raff, Brewton, \& Goin-Kochel, 2015).

Understanding the reasons why families select particular treatments for autism and the impacts these decisions have on child and family daily living will enhance service providers’ understanding of the barriers encountered, the family's goals, and the impact of these strategies 
on daily living, which are of vital importance for service providers to consider when working with these families (Case-Smith \& Arbesman, 2008; Tomchek, LaVesser, \& Watling, 2010.

\section{Caregivers' Selection of Treatments for Autism}

Treatments for autism are typically sought to remediate the core symptoms of autism: poor social reciprocity and communication, and repetitive behaviors (Gaspar Al Alba \& Bodfish, 2011). Related goals of these treatments also may be to improve functional independence, quality of life, and to diminish family stressors related to the diagnosis (Myers \& Plauche Johnson, 2007). Parents' treatment priorities may center on their child's adaptive skills and specific behaviors related to performance for these skilled areas if they are delayed or emerging. Parents have reported trying a variety of treatments through trial and error, in the hope that something works (Hoogsteen \& Woodgate, 2013).

Another approach for treatment selection is based on the comorbidities associated with autism (Levy, Mandell, \& Schultz, 2009; Myers \& Plauche Johnson, 2007). These comorbidities are classified as developmental, psychiatric, behavioral, sensory, neurological (i.e., seizures), gastrointestinal, and sleep. Specific treatments related to these associated conditions may help alleviate the symptoms and also may indirectly impact the autistic behaviors related to poor socialization, poor communication, and repetitive behaviors. Treatments must match the family’s beliefs, priorities, and routines or they will be more of a hindrance than beneficial (Goin-Kochel, Mackintosh \& Myers, 2009).

Another consideration is that children with autism are often involved in multiple, different treatments. This makes it difficult to attribute observed changes to a specific intervention. Parents have reported using two to nine different treatments at one time (i.e., Bowker, D’Angelo, Hicks, \& Wells, 2011; Rogers \& Vismara, 2008). Green et al. (2006) also 
studied treatment selection for autism and described that the highest number of interventions reported from their survey of 111 options was 47 treatments currently used and 39 in the past.

Age and severity of autism also influence the number of treatments used. Specifically, younger children tend to be enrolled in more treatment activities, whereas older children with autism may have fewer treatments due to exhaustion of or lack of helpful treatments (Green et al., 2006). Research suggests that unsubstantiated treatments were rarely considered by caregivers during adolescence (Goin-Kochel, Myers, \& Mackintosh, 2007).

Davis (2010) described four potential influences on parental choices of treatments for their child with autism, providing insights into parents' frequent use of unsupported treatments. First, parents of children with autism experience high levels of stress and they may select treatments out of feelings of desperation and therefore willing to try almost anything. Second, parents do not want to think "what if I tried this?” Therefore, parents want to try everything possible in case that is the answer to their child's difficulties. Third, parents select treatments without strong knowledge of any available empirical evidence, evidence-based practices, or of the autism diagnosis itself. Finally, parents are confused by contradictory professional opinions regarding the variety of treatment options. Understandably, they often make decisions based on information gleaned from a variety of sources such as the internet, other families, or therapists (Davis, 2010; Green, 2007). The complexity of the diagnosis with its’ variability of symptoms may influence parents' views about treatments and lead them to believe that they just need to find the right combination of treatments to fit the unique needs of their child (Davis, 2010). Gaspar Al Alba and Bodfish (2011) found that if parents were surprised by the diagnosis of autism, they tended to select treatments that focused on the education environment. However, 
parents who suspected their child of having autism prior to the diagnosis focused on etiology, the risk of siblings having ASD, and receiving more education about the diagnosis.

\section{Caregivers’ Reasons for Discontinuing Treatments}

Parents reported discontinuing treatment for their child with autism due to the following reasons: lack of measurable progress, treatment no longer needed due to observed progress or other changes, desire to continue but could not due to factors outside of their control (e.g., moving to a new house, sudden illness or death in family), side effects were too severe, treatment was aversive, cost was too high, or the child's willingness to comply was poor (Bowker et al., 2011; Wong \& Smith, 2006). Medications were the most common treatment to be discontinued, followed by alternative diets, and physiological treatments. Reasons for stopping treatments were mostly attributed to lack of visible progress. However, treatment duration was not considered; most treatments do not result in instantaneous changes and require time before any effects may be observed. In one study, parents reported that participation in treatments for autism varied from a few days to many years (Wong \& Smith, 2006).

Stressors that may influence discontinuation of treatment are the child or family's responses to diagnostic and intervention services, child rearing abilities, financial status, rigid routines, respite care, parents’ work, and family socialization (Kuhaneck, Madonna, Novak, \& Pearson, 2015). Stressors are also commonly related to siblings’ presence in the home. Parents are fearful that their attention to their child with autism takes away from their other child(ren)'s needs. Treatments may be discontinued due to these added stressors which, in turn, confound the family's attention to the needs of the child with autism (Kuhaneck \& Britner, 2010).

\section{Treatments for Autism}


Autism presents in multiple ways. Every person with autism has unique personal characteristics, comorbidities, and family situation. Therefore, each individual with autism requires a personalized treatment plan to address this complexity (Autism Speaks, 2018). Currently, there are over 130 different treatments being used to treat autism. Families reportedly are trying numerous treatment strategies for their child with autism and determining for themselves which is most beneficial rather than waiting for evidence of effectiveness to be developed. Caregivers are constantly searching for those treatments that will yield positive change for their child (Goin-Kochel et al., 2007). Best outcomes are observed when caregivers are trained to take an active role in the selected treatments (Case-Smith \& Arbesman, 2008; Levy et al., 2009). Also, understanding parental beliefs about the child's disability may assist with the development of appropriate family treatments that can alleviate stress and promote family wellbeing (Al Anbar, Dardennes, Prado-Netto, Kaye, \& Contejean, 2010).

Professionals who work with children with autism (e.g., teachers, pediatricians, therapists) must also consider the variety of treatments that families may use in varying combinations (Goin-Kochel et al., 2007). On one hand, “combining treatments may be an effective and necessary way to treat these complex disorders, yet little is known about the safety and efficacy of combining treatment approaches” according to Bowker et al. (2011, p. 1379). On the other hand, the use of multiple treatments for autism at once can be harmful and counteractive. Sometimes combining treatments prevents optimal outcomes or limits resources (Call, Delfs, Reavis, \& Lomas-Mevers, 2015). Combining treatments may also hinder the ability to determine any specific intervention's effects on observed outcomes.

It is important to note that multiple professionals- even from the same profession- may be a part of the intervention team for a child with autism (e.g., a school-based occupational therapist 
and an outpatient occupational therapist). Professionals should support families through the effective coordination of care to address the multiple needs and symptoms related to the child's autism. Families must be aware of any contraindications with care (e.g., counterproductive techniques, medication interactions) and encourage collaboration with the team members, including the caregivers and child with autism. Green et al. (2006) suggested that practitioners should understand the parents' decision processes for treatment selection to better serve the population with autism.

Treatments can be categorized based on their area of emphasis for disease or disability management, setting in which they occur, or methodology and/or theories used. For purposes of this study, treatments for autism were categorized into seven main areas: behavioral, educational, medical, dietary, therapeutic, community-based, and complementary/ alternative medicine. Categorization of the treatments were determined through a systematic review process of the literature. Refer to Appendix B for the list of treatments within the categories.

\section{Behavioral Treatments}

Behavioral treatment is a widely used, empirically-based, successful treatment intervention for children with autism. These methods do not have strong evidence for elimination of the symptoms of autism, but have been shown to reduce undesirable behaviors and improve

academic performance. Behavior therapies are highly structured, define expectations clearly, are organized hierarchically, include measurable goals, and are easily integrated (Levy et al., 2009; Sheinkopf \& Siegel, 1998). Implementing behavioral-focused treatments is beneficial to assist in developing the child's communication and social skills, as well as for decreasing harmful reactions (e.g., self-injurious behaviors) that are unsafe and unhealthy (Lancaster, 2005). However, such treatments require significant time to implement and for carryover into 
multiple environments to be effective. Recommended time with a trained professional is 20-25 hours per week (Autism Speaks, 2018). Also, these programs have limited generalizability of skills into the community due to the high structure for implementation (Levy et al., 2009). The most frequently used behavioral treatments are the Lovaas Model (aka Applied Behavioral Analysis), Early Start Denver Model, floortime (DIR), and verbal behavioral therapy (Autism Speaks, 2018).

\section{Educational Treatments}

The educative treatments not only address academic learning, but may also impact social skills, self-care skills, communication, behaviors, and generalization of these skills across a wide range of environments (Myers \& Plauche Johnson, 2007). Early participation in structured educational programming has been strongly supported to be effective for better outcomes later.

The following is a listing of attributes and considerations that have been deemed as effective components in early education programs for children with autism. Children should begin these types of programs as soon as autism is suspected; families should not wait until a definitive diagnosis is given. The program should be intensive, developmentally appropriate, and systematically planned with specific objectives and a low student-to-teacher ratio with opportunities for small group activity. Opportunities for interactions with typically developing peers during specific education activities, as well as incorporating high levels of structure are reported as being effective components for early educational programs. These programs should use strategies that enable the child with autism to generalize the learned skills to new environments and situations. All of these aspects of these programs should include the family and provide training to assist with carryover in the home. Assessment-based curricula should guide the educational program and include communication, social skills, adaptive skills, behavior 
management, cognition, and developmentally appropriate readiness and academic skills (Myers \& Plauche Johnson, 2007).

\section{Medical Management and Treatments}

Attending to the medical needs of a child with autism can promote overall improvement of developmental skills, behaviors, and quality of life. Management of acute illness, sleep dysfunction, behaviors, psychiatric conditions, associated medical problems, as well as preventative care can positively influence children’s progress, especially their educational outcomes (Myers \& Plauche Johnson, 2007). Medical management can be most effective in treating autism if there is an understanding of the neurophysiolopathology of core symptoms as well as the pharmacogenetic approaches while considering the family history of drug responsivity (Palermo \& Curatolo, 2004).

Pharmacological treatments for autism are used to treat the core symptoms and comorbid conditions such as attentional difficulties, hyperactivity, affective difficulties, depression, repetitive behaviors, irritability, aggression, anxiety, self-injurious behavior, behavioral cycling between rage and euphoria, social impairment, destructive behaviors, and sleep disruption (Chez, Memon, \& Hung, 2004; Levy et al., 2009; McDougle, Stigler, Erickson, \& Posey, 2006; Myers \& Plauche Johnson, 2007; Palermo \& Curatolo, 2004). Efficacy of using pharmaceutical treatments for autism is well documented (Truven Health Analytics, 2018), however, using medication has been noted to be a last resort option for treatment selection by caregivers (GoinKochel et al., 2007).

\section{Therapeutic Treatments}

Therapy includes a variety of services through the lifespan, beginning at birth. Children with special needs may require speech and language therapy (SLT) to address social communication 
deficits, making it the most sought after therapy for autism (Tomchek et al., 2010). Use of augmented and alternative communication methods have limited published evidence; however, use of these devices can support learning to talk and help children understand symbolic communication (Myers \& Plauche Johnson, 2007).

Another frequently used therapy for autism is occupational therapy (OT), which provides effective support, resources, and advocacy to individuals with autism (Tomchek et al., 2010). One-on-one treatment sessions are more widely used by therapists than treatment in small or large groups. If groups are used, small ratios have been most effective (Watling, Deitz,, Kanny, \& McLaughlin, 1999). Other examples of therapeutic treatments for autism are music therapy, therapeutic riding, counseling, interactive metronome, sign language, facilitated communication, and exercise.

\section{Dietary}

Most children with autism have selective diets, but malnutrition is unlikely (Myers \& Plauche Johnson, 2007). Children with PDD-NOS were more likely to be placed on specialized diets (i.e., gluten free, yeast free, Feingold diet) than children with Asperger's and autism (Bowker et al., 2011). Hendren (2015) discussed when children with autism showed benefits (i.e., nutritional and metabolic status) after being given supplements. This may assist with protein and peptide digestion, especially for children who have gastrointestinal issues. By improving the function of the gut, better brain functioning is enabled through improvements in the production of amino acids: the gut-brain connection. Supplements with the most consideration from providers are vitamin $\mathrm{D}_{3}$ and omega-3 fatty acids

\section{Community-Based Intervention}


Individuals with autism and their families may have goals of being contributing members to society. Most adults with autism live with their parents or in community supportive living. A small percentage are employed and if they work many receive below average wages which impedes independent living (Taylor et al., 2012). Despite this, adolescents and young adults with autism can learn strategies to improve their chances to obtain paid employment. These situations can be either independent or supported employment. Employment has been shown to improve quality of life, autistic symptoms, and executive functioning skills in people with autism

(Weaver, 2015). Supported employment is more beneficial to people with autism than sheltered workshops with a work focus. Supported employment also is more beneficial than independent work because many individuals with autism live a dependent life (Taylor et al., 2012). Technology has been reported to be an effective tool for vocational skill attainment (Weaver, 2015).

\section{Complementary and Alternative Treatments}

Complementary and alternative treatments (CAMs) are described as medical care that is not standard practice, which can complement standard medical treatments, or be used instead of standard treatments (National Institutes of Health, 2015). Levy et al. (2009) stated that parents seem to select CAMs more often in association with autism than for any other childhood disability or disorder, even before receiving an official diagnosis. However, many of these treatments do not have strong evidence to support positive outcomes. Caregivers of children with autism most likely learn about these treatment options through networks with other parents or via the internet (Harrison \& Zane, 2018; Wong \& Smith, 2006) in which case the scientific evidence that supports these treatment options may be missing, misreported, or ignored. More than $50 \%$ of families with children with autism have used CAMs (Harrison \& Zane, 
2018). Parents' decisions to use CAMs for their child were correlated with education level of the parents and parents' use of CAMs for themselves, and related to the non-curative nature of autism (Wong \& Smith, 2006).

CAMs are divided into biological and non-biological categories. Biological treatments include immunoregulatory treatments, detoxification therapies, gastrointestinal treatments, and dietary supplements. Examples include supplements such as B6, magnesium ion, dimethyl glycine, and cod-liver oil; antibiotics, antifungals, antivirals, and immunoglobulins; gastrointestinal medications; chelation; hyperbaric oxygen chambers; and withholding of immunizations. Non-biological alternative treatments include manipulative, body-based, mindbased, and energy medicine. Examples of these include chiropractics with craniosacral manipulation, auditory integration, yoga, behavioral optometry, animal-assisted therapy, music therapy, massage, qigong, interactive metronome, reiki, and transcranial stimulation (Levy et al., 2009; Myers \& Plauche Johnson, 2007).

This study examined caregivers' perspectives regarding selection of treatment for their children with autism by (a) identifying what treatments that caregivers report most frequently selecting to treat their child with autism, (b) identifying why specific treatments are selected, and (c) identifying why the treatments are discontinued. The survey used in the current study listed 133 treatments that caregivers could report using currently or having previously used for their child with autism. While other studies have sought to understand why parents select particular treatments (e.g., Bowker et al., 2011; Green et al., 2006). However these studies have only selected a small number of autism treatments as part of their survey (e.g., Bowker et al., 2011; Goin-Kochel et al., 2007); have focused on specific treatments categories such as educational 
treatments (e.g., Hess, Morrier, Heflin, \& Ivey, 2008; Pituch et al., 2011); or focused on a specific age such as early intervention (e.g., Rogers \& Vismara, 2008).

\section{Method}

A sequential explanatory mixed methods research design with semi-structured interviews following an online survey was implemented (Greene, Carracelli, \& Graham, 1989). Interview participants were purposefully sampled based on survey response profiles (see Figure 1 for design).

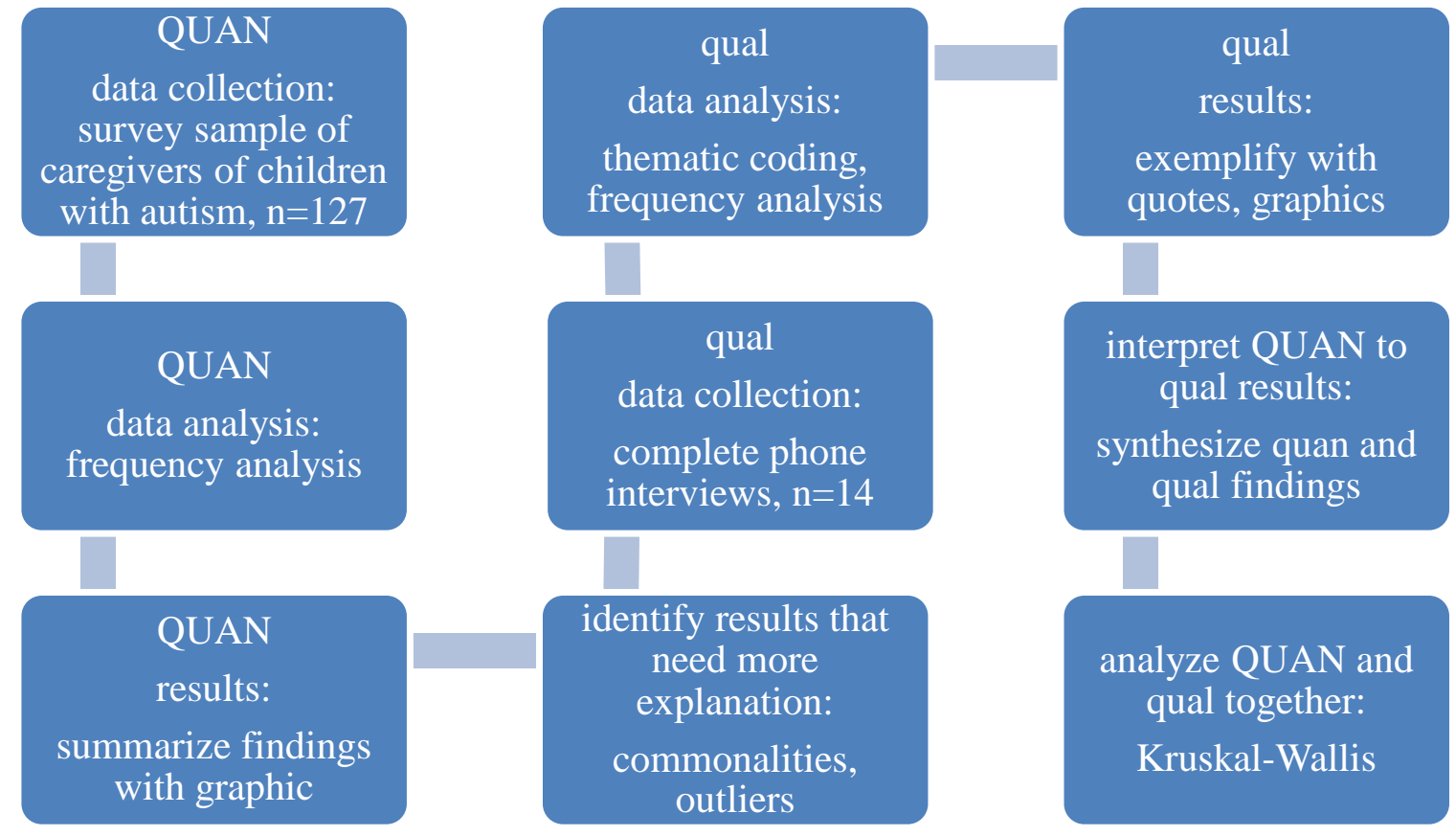

Fig. 1 Sequential Explanatory Mixed Methods Design

\section{Participants}

Participants for the survey $(\mathrm{N}=127)$ were recruited by advertising on Facebook, the Autism Speaks website, and through the investigator's personal contacts at various pediatric clinics and schools throughout the U.S. There were 174 caregivers who completed the survey, but 47 could not be used due to incomplete information or duplication between father and mother of a given autistic child. For the duplications, the first survey completed as per the time stamp on Qualtrics 
was the data used for this study. There were 100 mothers (78.74\%), 16 fathers (12.60\%), three adoptive mothers (2.36\%), one grandmother (0.79\%), four aunts (3.15\%), one sibling (0.79\%), and two guardians (1.57\%). Of these respondents, 117 (92.86\%) were white, five (3.97\%) were Hispanic/ Latino, two (1.59\%) were black/ African American, two (1.59\%) identified as other, and one participant preferred not to answer. The participants were located in the following states: 67 from West Virginia; 28 from Pennsylvania; five from Ohio; two each from North Carolina, South Carolina, Kentucky, Nebraska, and Florida; and one each from Colorado, Michigan, Massachusetts, California, New York, Texas, Washington, and Alabama. Nine caregivers did not identify their location. Participants’ median household income was \$50,000-\$74,000. Education level of the survey respondents were: one completed some high school, 32 graduated from high school, 10 completed vocational school, 28 graduated with an associate’s degree, 29 with a bachelor's degree, 20 with a master's degree, and 5 with a doctorate. Two participants preferred to not answer.

The children with autism that the caregivers reported on included 101 males and 22 females; 4 respondents did not identify their child's gender. Five of the children reported on were toddlers (1-3 years old), 20 were preschool aged (3-5 years old), 57 were school aged (5-11 years old), 32 were adolescents (12-17 years old), and nine were young adults (older than 18).

The interview sample $(n=14)$ consisted of 13 biological mothers and one grandmother, and all were Caucasian. They were located in West Virginia (n=6), Pennsylvania (n=4), Nebraska $(n=1)$, North Carolina $(n=1)$, New York $(n=1)$, and Colorado $(n=1)$. Three caregivers completed a high school education, two with a vocational education, three with an Associate's degree, two with a Bachelor's degree, two with a Masters, and two with a Doctorate. The children whom were reported on were 11 males and three females, of which three were identified with level 1 
ASD, five with level 2, two with level 3, and four with an unknown level of ASD. One child was a toddler, two children were of preschool age, six were school-aged, three were adolescents, and two were young adults.

The inclusion criterion was that their child had been diagnosed as having autism. Children could be of any age. Parents who agreed to complete the online survey consented to their participation by proceeding to Question \#1 after reading the introduction script and selecting "I agree to participate.” Participants for the interview were selected among caregivers who completed the survey and reported that they were willing to participate in a phone interview. Of the 127 participants who completed the online survey, 86 (67.7\%) reported they were willing to participate in a phone interview. Interview participants were purposefully selected to include seven respondents who selected treatments most commonly selected within each intervention category and an additional seven respondents who selected treatments that were least commonly selected by the total sample.

\section{Measures}

An online questionnaire designed by the researcher was deployed on the Qualtrics platform. The questionnaire included Likert scale items, multiple choice selections, and brief narrative answers. Questions included: demographics of the family and child with autism including medical history and current functional level, information about the treatments previously used or currently being used, and personal perspectives on the autism diagnosis. The list of treatments on the survey was derived through a systematic review process via the university’s library website using the keyword combinations of autism, autism spectrum disorders, ASD, intervention, treatment. Pilot testing was completed with five caregivers of children with autism 
to assess content validity and determine that the survey items were applicable to the topic of study and easily understood by the participants.

Selected caregivers also participated in semi-structured telephone interviews to gather more personal information in regards to treatment selection and discontinuation for their child with autism. An introduction script was used prior to asking the guiding questions for the semistructured interview to build rapport with the participants (See Appendix A).

\section{Procedure}

Approval from the Institutional Review Board was obtained prior to data collection. Participants were recruited through advertising with Autism Speaks, on Facebook, and through personal contacts at various pediatric clinics and schools throughout the US. Participants consented to participate by selected "I agree to participate" after reading a cover letter for the study which was included as the first page on the Qualtrics survey. All participants were also screened for inclusion criteria by answering the first question on the questionnaire: "Do you have a child with autism.” If the participant answered "no", the questionnaire ended.

Once the questionnaire screening was completed to identify participants for the high and low frequency groups, a sub-sample was purposefully selected to form the group of participants to be interviewed. All interview participants were consented at the beginning of the interview. The telephone interviews were tape-recorded and transcribed by the researcher.

Respondents who completed the survey were subsequently emailed a \$10 Amazon gift card, and those who completed the phone interview received a \$30 gift card. This project was funded by the Mike Reed Student Research Award through the [university’s] Foundation.

\section{Data Analysis}


Descriptive statistics were compiled on caregiver and child characteristics (e.g., caregiver education, household income, ethnicity, and child gender, age, and ASD-specific diagnosis). Response frequencies were determined for each identified intervention (e.g., ABA, occupational therapy, gluten free diet, TEACCH, massage) and category type (i.e., medical, dietary, therapeutic, complementary/ alternative medicine (CAM), community-based, behavioral, and educational), based on level of use (i.e., tried, but not currently using; currently trying; see Appendix B). An independent samples Kruskal-Wallis H-Test was completed to determine whether a significant difference was present among treatment categories for treatments used by caregivers. Lastly, frequency counts were computed from the interview questions. The answers to the interview questions were coded based on a content analysis following Kvale and Brinkmann’s (2009) methodology. Open coding for common themes relating to reasons for selection and discontinuation was done, as well as selective coding of reasons why treatments were used. Frequency counts were computed for thematic codes (quantitization) following Sandelowski, Voils, and Knafl (2009).

\section{Results}

\section{Treatments Used: Past and Present}

Caregivers reported currently using treatments based on overall treatment category as follows: educational (28\%), community (27\%), therapeutic (26\%), behavioral (21\%), medical (21\%), dietary (20\%), and CAMs (12\%). They also reported treatments tried but not currently using as follows: therapeutic (20\%), dietary (17\%), educational (17\%), behavioral (16\%), medical (12\%), community 11\%, and CAMs (6\%, see Figure 2). A Kruskal-Wallis H-test showed no statistically significant difference in usage (past and current) across treatment categories for the overall population $(\mathrm{p}=0.423)$. 


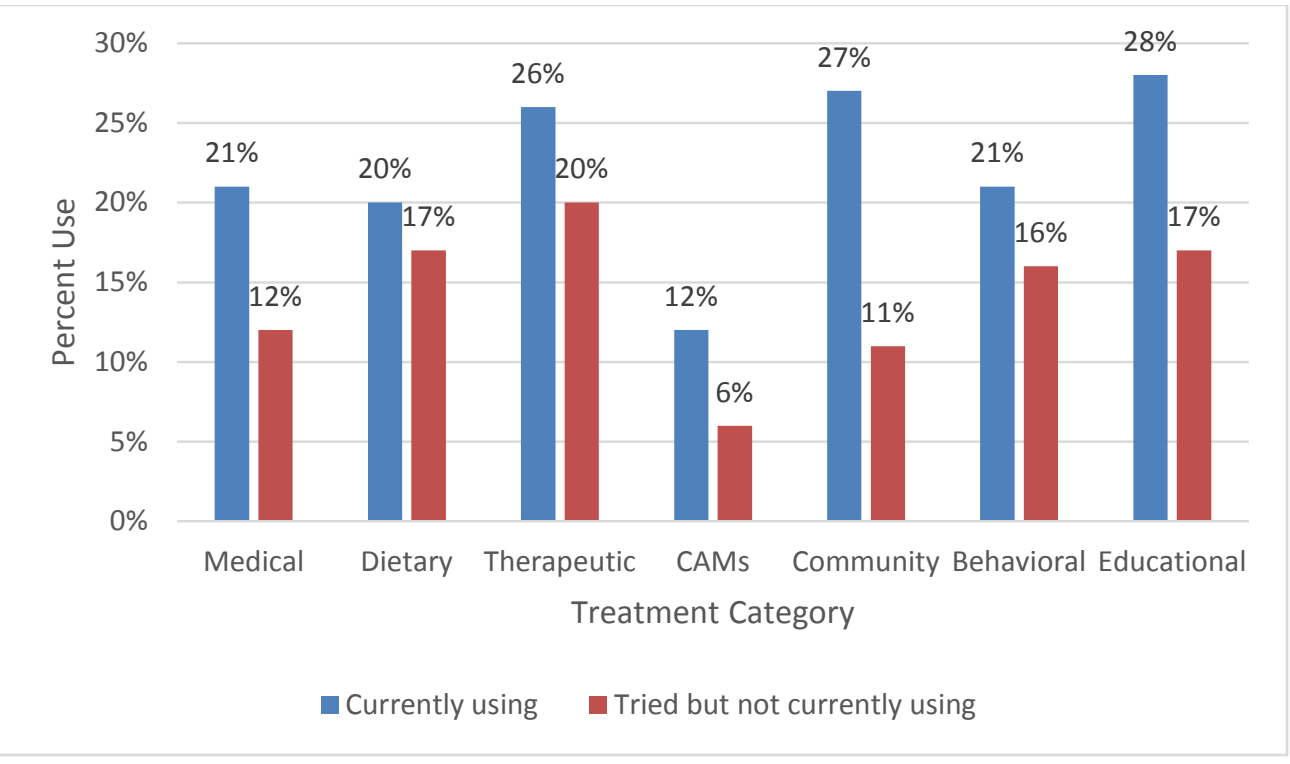

Fig. 2 Comparison of percent use of treatments currently using verses tried but not currently by caregivers of children with autism (n=127)

Thirty-one children were identified as level 1 ASD, 30 with level 2, and 23 with level 3. Two participants classified their child as having Atypical Autism, and 41 participants reported not knowing the level associated with the ASD diagnosis, which data were not used for this analysis. A Kruskal-Wallis test showed no significant difference in the number of treatments used across levels of ASD ( $\mathrm{p}=.261)$. Level 1, 2 and 3 ASD utilized treatments disaggregated by category as follows respectively: medical (25\%, 26\%, 25\%), dietary (30\%, 31\%, 21\%), therapeutic (33\%, 34\%, 34\%), CAM (13\%, 9\%, 13\%), community-based (27\%, 29\%, 24\%), behavioral (21\%, 36\%, 19\%), and educational (27\%, 37\%, 33\%). A Kruskal-Wallis H-test showed that there was a statistically significant difference between therapeutic intervention use and CAM use across levels of ASD ( $\mathrm{p}=0.009$ ); all other comparisons were not significant (Refer to Figure 3). On average, level 1 ASD children used (past and present combined) 34.06 treatments, level 2 used 40.8, and level 3 used 34.91. During the interviews, the caregivers who had children with level 1 
ASD reported that their children responded negatively to behavioral interventions whereas this was not a topic of discussion for other levels of ASD.

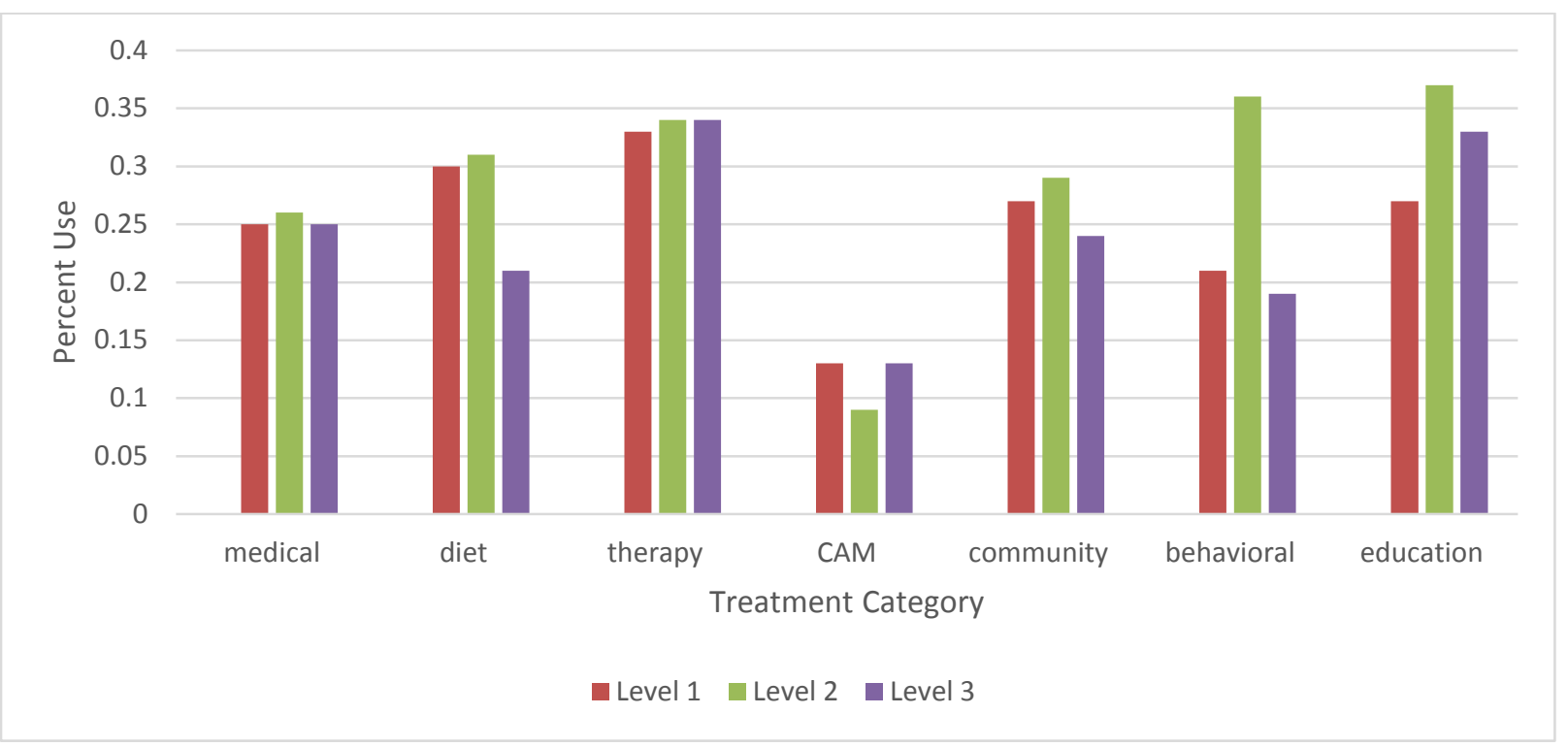

Fig. 3 Percent use of treatments for autism by intervention category for each level of ASD diagnosis (level 1, $\mathrm{n}=31$; level 2, $\mathrm{n}=30$; level 3, $\mathrm{n}=23$ )

Of the 133 autism treatments listed on the survey, caregivers reported medication and a psychologist (57\%) as the most frequently used medical intervention, followed by a psychiatrist (53\%) and a neurologist (46\%). The most frequently used dietary treatments were vitamins and supplements (72\%), gluten free diet (39\%), and a nutritionist (35\%). The caregivers reported using occupational therapy the most as a therapeutic intervention (89\%), followed by speech and language therapy (84\%), and early intervention (72\%). For CAMs, the most frequently used treatments were reported to be relaxation techniques (e.g., deep breathing, 60\%), then aromatherapy (39\%), and yoga (27\%). Advocacy support (63\%), autism support groups (58\%), and religious and spiritual activities (43\%) were reported to be the most frequently used community-based treatments for autism. The most common behavioral treatments the caregivers reported using with their child were positive reinforcement (82\%), positive behavioral support 
(54\%), and applied behavioral analysis (ABA, 50\%). For education treatments, Individualized Education Programs (IEPs, 72\%) were used the most, followed by school-based speech therapy (70\%), and school-based occupational therapy (67\%, see Figure 4). It is important to note that some survey respondents listed home schooling $(\mathrm{n}=12)$ as a treatment although this was not included on the survey. Interview participants also mentioned home schooling ( $n=6)$ as a treatment used when support in public education was not optimal for their child with autism.

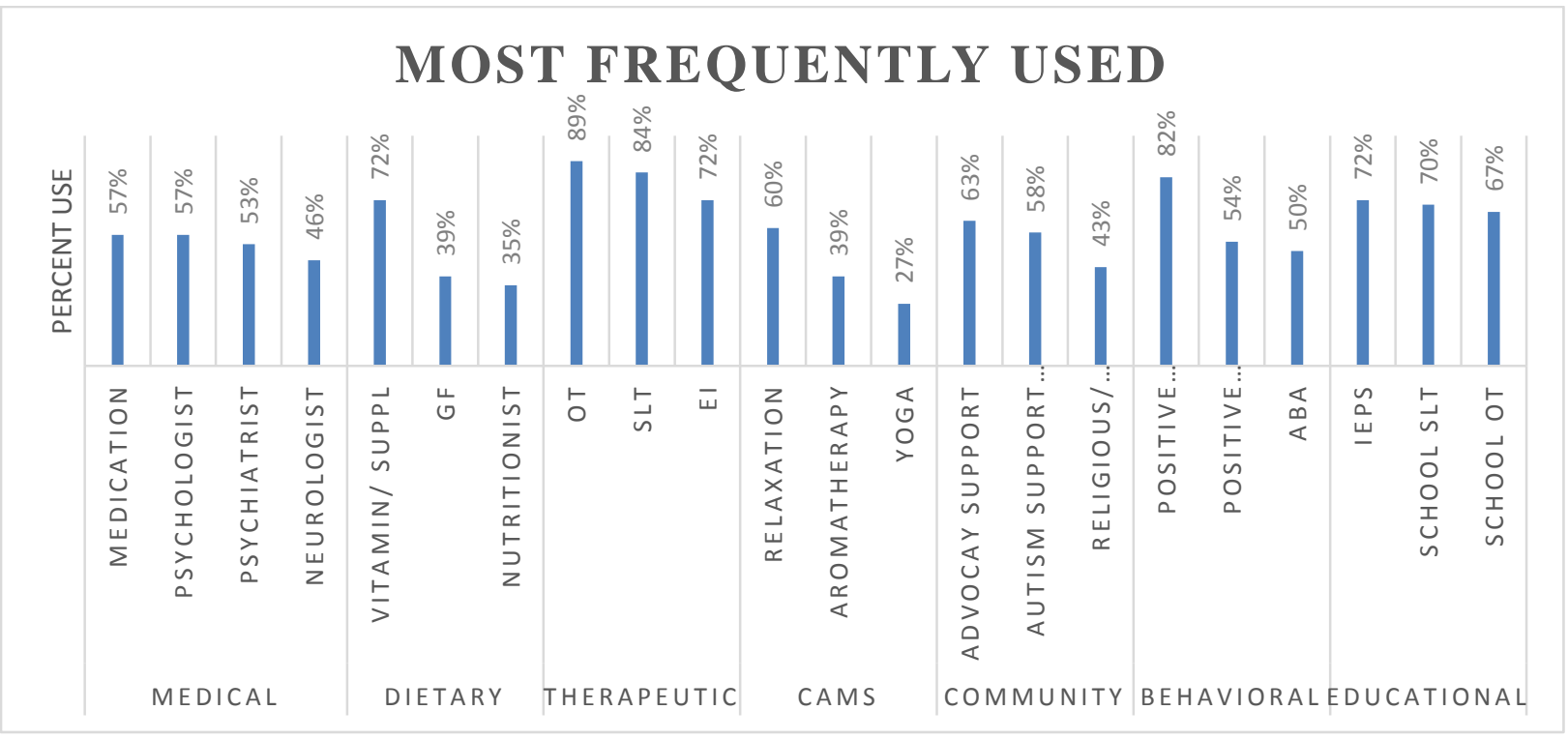

Fig. 4 Percent use of the most frequently used treatments by category. (suppl- supplements, GFgluten free, OT- occupational therapy, SLT- speech language therapy, EI- early intervention, ABA- applied behavior analysis, IEPs- individualized education program, CAMscomplementary and alternative)

Intravenous chelation (4\%), transfer factor pentoxifyllinbasic fibroblast growth factor (BCGF, 6\%), and chelation pills (6\%) were reported to be the least frequently used medical treatments. For dietary, the Feingold diet (6\%), yeast free diet (13\%), and low carbohydrate or carbohydrate free diet (17\%) were the least used. The smallest frequency use of therapeutic treatments were interactive metronome (8\%), Bolles sensory leaning program (9\%), and dance 
therapy (12\%). Few caregivers reported using transcranial stimulation and qigong (4\%), and acupuncture, Buddhist monk interactions, and Watsu (5\%). Among community-based treatments, sheltered workshops (4\%), supported employment (10\%), and job coaching (13\%) were least used. Least used behavioral treatments were enriched supportive therapy (EST, 7\%), cognitive enhancement therapy (CET) and pivotal response training (9\%), and neurofeedback (12\%). Finally, partial hospitalization (6\%), Son-Rise program and weekend school support services (9\%), and responsive teaching (10\%) were the least-used educational treatments for children with autism (see Figure 5).

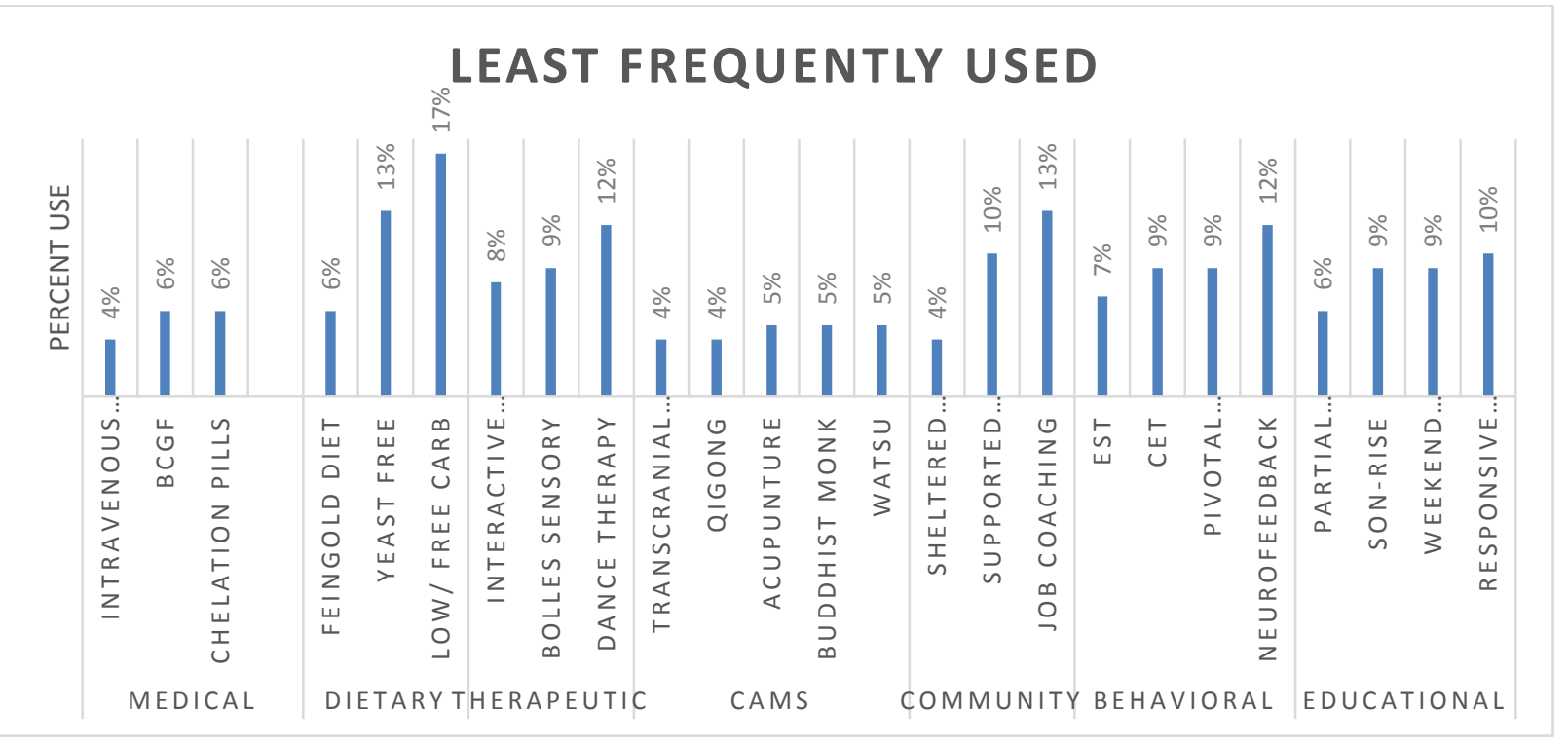

Fig. 5 Percent use of the least frequently used treatments by category. (BCGF- transfer factor pentoxifyllinbasic fibroblast growth factor, EST- enriched supportive therapy, CET- cognitive enhancement therapy, CAMs- complementary and alternative)

The sample also was divided into groups based on comorbidities of Sensory Processing Disorder ( $n=34)$, ADHD ( $n=45)$, or no comorbidities noted $(n=23)$. Other comorbidities were not consider due to low representation. Percent use of each intervention category per comorbidity type was respectively: medical (26\%, 26\%, 26\%), dietary (30\%, 33\%, 26\%), 
therapy (38\%, 39\%, 36\%), CAM (15\%, 16\%, 15\%), community (30\%, 33\%, 25\%), behavioral (31\%, 32\%, 25\%), education (38\%, 39\%, 32\%; see Figure 6). On average, children with ASD and a comorbidity of sensory processing disorder used 32.91 treatments, those with a comorbidity of ADHD used 43.6 treatments, and those with no comorbidities used 37.18 treatments. A Kruskal-Wallis test showed no significant difference in number of treatments used across comorbidity groupings $(\mathrm{p}=.220)$.

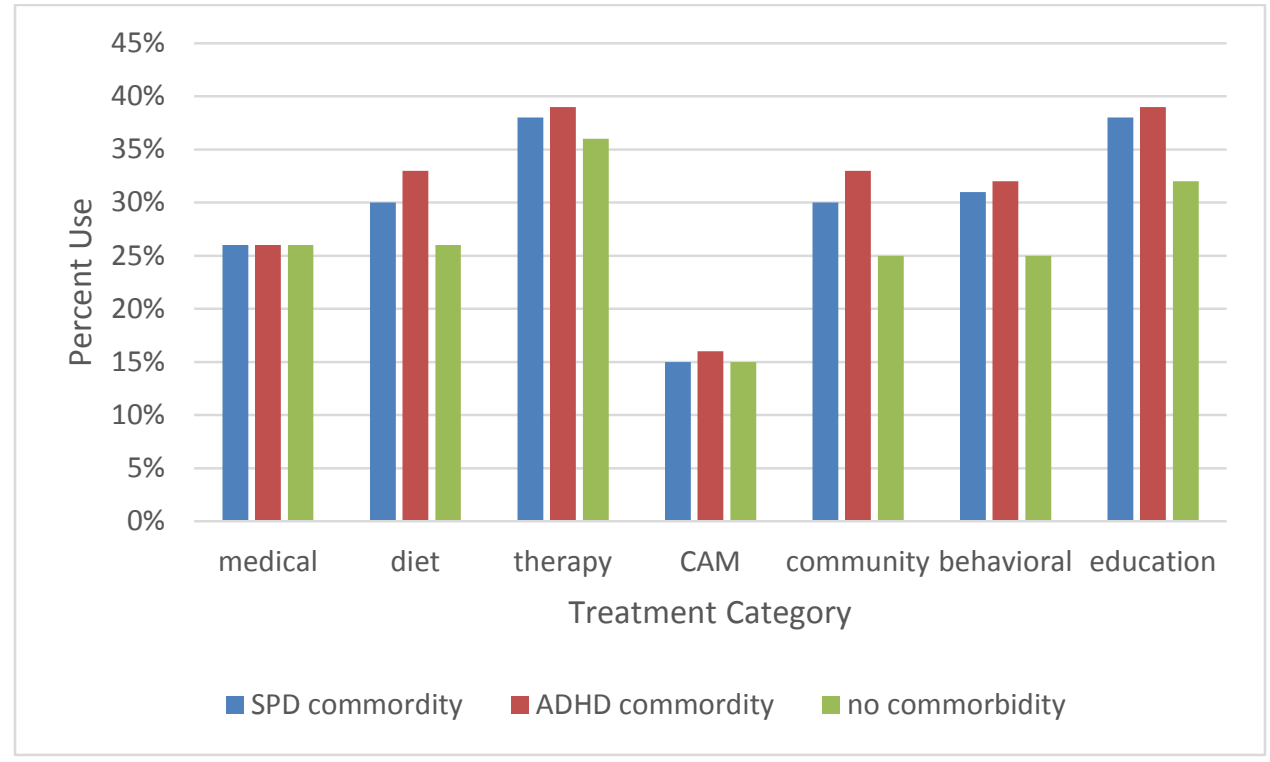

Fig. 6 Percent use of treatments for autism by category for comorbidity groups of Sensory Processing Disorder (SPD, $\mathrm{n}=34)$ and Attention Deficit Hyperactivity Disorder $(\mathrm{ADHD}, \mathrm{n}=$ 45), and no comorbidities noted $(n=23)$

\section{Reasons for Selection of Treatments}

As per qualitative analysis from the interviews $(n=14)$, caregivers most frequently reported they selected treatments based on their own research $(n=7)$, or that they simply went along with recommendations of professionals $(n=7)$. Treatments were also selected based on the desire to improve their child's quality of life for long term impact $(n=5)$ as well as trial and error approaches $(n=5)$. Less common reasons for selecting treatments included worry about 
overloading the child or taking the autism away $(n=3)$, addressing specific deficits $(n=3)$, need for professional support $(n=3)$, and resources $(n=1)$. See Figure 7 for examples given by the caregiver interview sample for each theme for selection of treatment for autism.

\begin{tabular}{|c|c|}
\hline $\begin{array}{l}\text { Themes for Selection of } \\
\text { Treatments }\end{array}$ & Participant Comments Supporting Theme \\
\hline Own research & $\begin{array}{l}\text { "I want to be an expert on autism. After you get a diagnosis like } \\
\text { that, you read everything, you look up everything, you ask the } \\
\text { doctor, friends, just anyway I can get information, I'll take it." }\end{array}$ \\
\hline $\begin{array}{l}\text { Recommendations of } \\
\text { professionals }\end{array}$ & $\begin{array}{l}\text { "We got a new pediatrician and she recommended birth-3 and we } \\
\text { had PT and the physical therapist was like this is what you need } \\
\text { to do. ...through birth to three we added OT, nutritionist..." }\end{array}$ \\
\hline Improve QOL & $\begin{array}{l}\text { "He needs a better quality of life. We need the skills, we can’t do } \\
\text { it without some sort of intervention.” }\end{array}$ \\
\hline Trial and error & $\begin{array}{l}\text { “...trial and error a lot of times. He is ever changing. ... I know a } \\
\text { lot of people from my job if they suggest something, I’ll try it.” }\end{array}$ \\
\hline Encumber & $\begin{array}{l}\text { “Also not overloading it, life is worth living, has to be play based } \\
\text { and fun.” } \\
\text { "We haven’t done a lot, avoided behavior approaches, don't want } \\
\text { to squash his personality and creativeness, we don’t view his } \\
\text { autism as a failing on his part. Unique challenges and unique } \\
\text { benefits, interventions are focused on that mindset.” }\end{array}$ \\
\hline Address specific needs & "I guess I just thought it would help him with certain things." \\
\hline Need for professional & “... then we realized we can’t do this at all, we need help. He \\
\hline
\end{tabular}




\begin{tabular}{|ll|}
\hline support & needs a better quality of life." \\
\hline Good use of resources & "Just thinking what will help him long term and what is the best \\
& investment at the time."
\end{tabular}

Table 1. Themes for treatment selection by caregivers of children with ASD for the interview sample

\section{Reasons for Treatment Discontinuation}

Caregivers reported discontinuing treatments due to their child not needing them anymore $(n=6)$, lack of child-professional/ parent-professional relationships $(\mathrm{n}=3)$, and negative responses to treatments $(n=3)$. Provider professionalism $(n=2)$, difficulty in access to treatments $(n=2)$, and waste of resources $(n=2)$ were also cited reasons for stopping participation in treatments for their child with autism. See Figure 8 for interview participant quotes to support each theme for discontinuation of treatments for ASD.

\begin{tabular}{|l|l|}
\hline Themes for & Participant Comments Supporting Theme \\
Treatments & "OT twice stopped, both times because they had taught him \\
\hline Not needed & "Norything they could teach him." \\
& "The other one [therapist], she and I clashed...” \\
\hline Lack of relationships & stop." \\
\hline Negative responses & that is not wherapy. If a therapist he likes is leaving it is time to \\
\end{tabular}




\begin{tabular}{|c|c|}
\hline & hurting herself." \\
\hline Provider professionalism & $\begin{array}{l}\text { “... there were many days that she [therapist] wouldn't even } \\
\text { show up for the therapy or she would come two days later. She } \\
\text { would come one out of every } 5 \text { times, it was very erratic. I have } \\
\text { anxiety like terrible and so I would get massively stressed out, it } \\
\text { just wasn't helpful to the situation. So we dropped the [therapy].” }\end{array}$ \\
\hline Difficult to access & $\begin{array}{l}\text { "[We] did gluten free and at that time it was so hard to find the } \\
\text { food." }\end{array}$ \\
\hline Waste of resources & $\begin{array}{l}\text { "We did do music therapy for a while but it got too expensive } \\
\text { because [its] not paid for by insurance. I wish it was something } \\
\text { that was covered. She really loved it. Thirty dollars for a one } \\
\text { hour session each week. It adds up." }\end{array}$ \\
\hline
\end{tabular}

Table 2. Themes for treatment discontinuation by caregivers of children with ASD for the interview participants

\section{Discussion}

This study shows a different perspective of treatment selection from previous studies done on this topic (e.g., Bowker et al., 2011; Goin-Kochel et al., 2007; Green, et al., 2006). Overall, therapeutic and educational treatments were most frequently used, while CAMs were used to a lesser extent. Occupational therapy, speech and language therapy, and positive reinforcement were the treatments reported to be mostly used for children with autism.

Caregivers of level 1 ASD children reported that they most frequently utilized dietary and therapeutic treatments. Caregivers of level 2 ASD children most commonly used behavioral and educational treatments, and used all treatments, except CAMs, at a higher percentage than the 
other levels. Caregivers of level 3 ASD mostly sought out therapeutic and educational treatments. CAMs were the least used across all levels possibly due to decreased access and awareness of these treatments. Providers may also refer less frequently to CAMs due to the lack of evidence support for effectiveness to impact autism concerns and comorbidities. Furthermore, a high percent of caregivers ( $n=41,32.3 \%$ ) were unaware of their child's ASD severity level. Knowledge of severity, which is related to developmental levels, is an integral part of the treatment process to understand limitations and skills of the child for purposes of planning, referrals, and progression through intervention (Kelly \& Plunkett D’Avignon, 2014).

As per this study, caregivers reported using a high number of treatments (average of 37 for past and presently used) as compared to previous studies (average of 15 for past and present; e.g., Goin-Kochel et al., 2007). "It is difficult to judge whether these numbers of treatments used should be considered too much, too little, or the right amount” (Green et al., 2006, p. 81). Also, each of the 133 treatments listed on the survey were reported as having been used by one or more of the caregiver survey respondents. This raises concerns as some of the treatments are harmful, are expensive to implement or maintain, or lack evidence regarding their effectiveness. Providers should understand all aspects, variations of, and intervention options available to better guide caregivers with supports for their child. Benefits of using evidence-based practice ensure good use of resources and the treatments are efficacious. "Many health plans apply evidencebased approaches to coverage decisions” (Garber, 2001, p. 62).

Treatments vary in their effectiveness for individuals with autism. Many autism treatments are individually tailored to meet the client's specific needs. Without resorting to trial and error, caregivers reported that they fear missing the opportunity for change and improvement for their 
child. Another participant eloquently described her challenges with treatments for her son. She stated:

Nobody could tell me that this could be the best things. Why did I try all these things, in desperation.... turn off that noise when you are feeling really desperate and you are more vulnerable. .... because you think maybe red dye \#40 would be the reason. At some point you just grasp at anything that would help.

Children with ASD present with variability in development. This unpredictability can cause increased stress for caregivers because the inconsistencies can be confusing causing the caregivers to reach for solutions (Kelley \& Plunkett D’Avignon, 2014).

Comorbidities are common alongside of ASD, specifically ADHD and SPD. Children with autism who had a comorbidity of ADHD were more likely to use treatments across the seven categories as compared to those children either without comorbidities or having a comorbidity of SPD. Providers for autism should be aware of the comorbid conditions the child has because these may be a direct indicator for treatment selection (Gaspar Al Alba \& Bodfish, 2011; Pituch et al., 2011). For example, consider two children with distractibility. One child who has sensory processing disorder may be overwhelmed with environmental stimuli and become distracted. They may benefit from sensory integration. Whereas a child with ADHD is also distracted but due to attention issues. These attention deficits could be successfully treated with medication. There is value to understanding comorbid conditions to support treatment selection for autism. One participant stated:

[There] needs to be a little more awareness to other conditions that go along with autism 
that's not related to autism. A lot of kids have other medical aspects. Because parents are not aware of it .... really try to understand all the variables, what is going on that is making this situation so unbearable at this moment to help them.

The complexity of ASD combined with other diagnoses needs to be considered when developing treatment plans, recommendations, mentoring, and educational goals. Using a needs-based phenomenon (i.e., focusing on the person-specific deficits) and emergent skills perspective for selecting treatments would enable practitioners to better support caregiver and patient needs (Hoogsteen \& Woodgate, 2013).

An intervention not included in the survey was home schooling. Interview participants reported using home schooling either permanently or intermittently throughout their child's education career for a variety of reasons, including bullying, lack of appropriate supports, school staff's underestimation of the child's abilities, and fear of public schooling. This concept should be an important issue for educational programs to attend to as legal issues can arise. The Individuals with Disabilities Education Act (IDEA, 2004) Part B specifically outlines what is required by schools for students with identified disabilities to receive a free appropriate public education in the least restricted environment. IDEA Part B provides guidance for managing disputes when services are not rendered or the parents and the school do not agree on necessary accommodations. Through procedural safeguards, dispute resolution options are provided by IDEA to guide parents with negotiations for what is best for their child in public education (Lee, 2019).

Children with level 1 ASD are sometimes overlooked by the schools because their child does not have an apparent disability. Parents also reported that a lack of knowledge about autism by 
the school personnel was a frequent deterrent to continuing in the school system. As one participant shared about her son:

He might be fine one minute and then a fire alarm can go off and he starts holding his ears and rocking back and forth. He keeps his composure and he gets upset and busts out crying because he has been holding everything in all day. And you try to explain it to the school and they say 'he doesn't do that here.' Well of course not because he wants to be as normal as he can around the other kids.

Another relationship that was disclosed during the interviews was the negative reactions that children with level 1 ASD have when given behavioral treatments. These parents reported that their child did not benefit from the behavioral treatments. For example, one participant reported: Behavior treatments, none of those things work. His affect is generally flat. You could take things away .... [he does] the same behavior with a different medium. I think really at the higher end [of the spectrum] .... it's a very different thing from a nonverbal child, so different.

A consideration regarding this idea would be the concrete, non-pragmatic thinking of level 1 autistics. Behavioral treatments, such as reinforcement or punishment, do not make sense because children with level 1 ASD see and understand the situation differently; therefore, they do not respond as expected but as they understand how their response should be based on their experiences. These deficits for level 1 ASD could be associated with the limitations for use and understanding of language in regards to context and decreased understanding of nonverbal communication (Berenguer, Miranda, Colomer, Baixauli, \& Rosello, 2018).

Caregivers often learn about new treatments for autism through social networks (e.g., peers, support groups), professional networks (e.g., therapists, counselors), and their own independent 
research (e.g., internet, Wikipedia). As reported in this study, Fiske (2017) also described that parents have been left without guidance after receiving the diagnosis, being left to seek out treatment options and supports on their own. Also, caregivers of children with autism select treatments with little guidance from informed professionals. Parents reported that they teach themselves about what needs to be done to assist their child. Furthermore, some caregivers reported that they believed their child's autism to be a "gift" to their family and, therefore, they avoided treatments that might change some of their child's personal characteristics. Parents reported that their child's autism was empowering for many reasons such as advocacy, spirituality, and purpose.

There are several challenges associated with the reported reasons for discontinuing treatments for autism. Interview participants reported that the lack of relationships with their service providers made them stop. These caregivers did not consider the benefits gained from these services, just that they or their child was not positively engaging with their provider. Similarly, caregivers also reported that they discontinued treatments when the provider lacked professionalism. Both lack of professionalism and lack of rapport with the child with autism and their families can be addressed through training, education, and mentorship programs for these service providers. However, with advocacy and team communication these areas can be improved on and service providers, such as teachers, pediatricians, therapists, can better serve the autistic community as well as increase access to competent autism providers (Kelly \& Plunkett D’Avignon, 2014). Being family centered helps family functioning and coping with the diagnosis. "Systematic stressors, such as problems obtaining appropriate diagnoses or services, also make parenting a child with an ASD more challenging than it might otherwise be” (Kuhaneck \& Britner, 2010, p.275). 


\section{Limitations}

Limitations included small sample size and limited geographic region surrounding WV and PA. Caregivers also may not be aware of other treatments being used within other programming (i.e., the specific behavioral educative techniques used in the classroom or in therapy sessions). The study relied on caregivers' self-report data, which is subject to bias due to selective memory of participants, social desirability, and other factors that might influence how participants responded to the survey and interview protocols.

\section{Contributions of This Research}

This study may serve to inform providers (i.e., teachers, therapists, pediatricians, psychiatrists) about the reasons why caregivers select particular treatments for their child with autism. This information is important for these providers to know because as there is no known cause for autism, and no single intervention has been shown to either cure or directly alleviate the symptoms of autism. Providers should consider all of the factors that may influence caregivers' selection of treatments. These factors include focus on improved quality of life and specific deficit areas of function, trial and errors methods, and good use of resources. Caregivers also emphasize the importance of not restricting their child to only autism focused activities to allow them to be who they are meant to be. Supporting families in the decision-making process around treatments will enable more effective parent-provider collaboration, which may contribute to better child outcomes. By having knowledge of how caregivers select treatment, providers can intervene at appropriate levels of functioning. For example, if a teacher is aware that their student with ASD is only receiving school-based therapy services with an IEP then they can better guide the child's educational team for supplemental activities to address unmet needs. 
The study reported here may inform other researchers about the treatments that are being selected by caregivers of children with autism. Some of these treatments may need to be examined more closely. A point topic that arose from the study was the negative perspectives of behavioral treatments with level 1 ASD. Behaviorist can examine their intervention outcomes by level of ASD. Also, if parents frequently use treatments that are harmful, then they need to be informed of this harm by pediatricians, psychologists, and other primary referrers. If caregivers use treatments that are wasteful and ineffective, then careful examination and reporting of results by intervention providers is needed. 


\section{References}

Al Anbar, N., Dardennes, R. M., Prado-Netto, A., Kaye, K., \& Contejean, Y. (2010). Treatment choices in autism spectrum disorder: The role of parental illness perceptions. Research in Developmental Disabilities, 31, 817-828. https://doi.org/10.1016/j.ridd.2010.02.007

American Occupational Therapy Association. (2018). The scope of occupational therapy services for individuals with an autism spectrum disorder across the life course. The American Journal of Occupational Therapy, 64(6), S125-S136. doi:10.5014/ajot.2010.64S125

Autism Speaks. (2018). DSM-5 diagnostic criteria. Retrieved from https://www.autismspeaks.org/what-autism/diagnosis/dsm-5-diagnostic-criteria

Berenguer, C., Miranda, A., Colomer, C., Baixauli, I., \& Rosello, B. (2018). Contribution of theory of mind, executive functioning, and pragmatics to socialization behaviors of children with high functioning autism. Journal of Autism and Developmental Disorders, 48, 430-441. doi: 10.1007/s10803-017-3349-0

Bowker, A., D’Angelo, N. M., Hicks, R., \& Wells, K. (2011). Treatments for autism: Parental choices and perceptions of change. Journal of Autism Developmental Disorders, 41, 13711382. doi: 10.1007/s10803-010-1164-y.

Call, N. A., Delfs, C. H., Reavis, A. R., \& Lomas-Mevers, J. (2015). Factors influencing treatment decisions by parents for their children with autism spectrum disorder. Research in Autism Spectrum Disorders, 15, 10-20. doi: http://dx.doi.org/10/1016/j.rasd.2015.04.001

Case-Smith, J., \& Arbesman, M. (2008). Evidence-based review of treatments for autism used in or of relevance to occupational therapy. The American Journal of Occupational Therapy, 62, 416-429. doi:10.5014/ajot.62.4.416

Centers for Disease Control. (2017). Autism spectrum disorder: Data and statistics. Retrieved 
from https://www.cdc.gov/ncbddd/autism/data.html

Chez, M. G., Memon, S., \& Hung, P. C. (2004). Neurological treatment strategies in autism: An overview of medical intervention strategies. Seminars in Pediatric Neurology, 11(3), 229-235. doi: 10.1016/j.spen.2004.07.007

Davis, T. N. (2010). Unsubstantiated treatments for individuals with autism [Editorial]. Developmental Neurorehabilitation, 13(4), 231-233. doi: 10.3109/17518421003793439

Fiske, K. E. (2017). Autism and the family. New York: W. W. Norton \& Company, Inc.

Garber, A. M. (2001). Evidence-based coverage policy. Health Affairs, 20(5), 62-81. doi: https://doi.org/10.1377/hlthaff.20.5.62

Gaspar Al Alba, M., \& Bodfish, J. W. (2011). Addressing parental concerns at the initial diagnosis of an autism spectrum disorder. Research in Autism Spectrum Disorders, 5, 633-639. doi: 10.1016/j.rasd.2010.07.009

Goin-Kochel, R. P., Mackintosh, V. H., \& Myers, B. J. (2009). Parental reports on the efficacy of treatments and therapies for their children with autism spectrum disorders. Research in Autism Spectrum Disorders, 3, 528-537. doi: 10.1016/j.rasd.2008.11.001

Goin-Kochel, R. P., Myers, B. J., \& Mackintosh, V. H. (2007). Parental reports on the use of treatments and therapies for children with autism spectrum disorders. Research in Autism Spectrum Disorders, 1, 195-209. doi: 10.1016/j.rasd.2006.08.006

Green, V. A. (2007). Parental experiences with treatments with autism. Journal of Developmental and Physical Disabilities, 19, 91-101. doi: 10.1007/s10882-007-9035-y

Green, V. A., Pituch, K. A., Itchon, J., Choi, A., O’Reilly, M., \& Sigafoos, J. (2006). Internet survey of treatments used by parents of children with autism. Research in Developmental Disabilities, 27, 70-84. doi: 10.1016/j.ridd.2004.12.002 
Greene, J. C., Caracelli, V. J., \& Graham, W. F. (1989). Toward a conceptual framework for mixed-method evaluation designs. Educational Evaluation and Policy Analysis, 11(3), 255- 274.

Harrison, K. L., \& Zane, T. (2018). Is there science behind that? Autism and complementary medicine. Science in Autism Treatment, 15(2), 10-13. Retrieved from asatonline.org

Hendren, R. L. (2015). Omega-3, vitamin D3, and melatonin. In clinical round-up, Alternative and Complementary Therapies, 21(2), 92-93. doi: 10.1089/act.2015.21208

Hess, K. L., Morrier, M. J., Heflin, L. J., \& Ivey, M. L. (2008). Autism treatment survey:

Services received by children with autism spectrum disorders in public school classrooms. Journal of Autism and Developmental Disorders, 38, 961-971. doi: 10.1007/s10803-007-0470-5

Hoogsteen, L., \& Woodgate, R. L. (2013). Centering autism within the family: A qualitative approach to autism and the family. Journal of Pediatric Nursing, 28, 135-140. http://dx.doi.org/10.1016/j.pedn.2012.06.002

Individuals with Disabilities Education Act, 20 U.S.C. § 1400 (2004).

Kelly, L., \& Plunkett D’Avignon, J. (2014). Charting the course for treating children with autism. New York: W. W. Norton \& Company, Inc.

Kuhaneck, H. M., \& Britner, P. A. (2010). The impact of an autism spectrum disorder on family occupations. In H. M. Kuhaneck \& R. Watling (Eds.), Autism: A comprehensive occupational therapy approach, 3rd ed (pp. 255-280). Bethesda: American Occupational Therapy Association.

Kuhaneck, H. M., Madonna, S., Novak, A., \& Pearson, E. (2015). Effectiveness of treatments for children with autism spectrum disorder and their parents: A systematic review of family 
outcomes. The American Journal of Occupational Therapy, 69, 6905180040.

http://dx.doi.org/10.5014/ajot.2015.017855

Kvale, S., \& Brinkmann, S. (2009). InterViews: Learning the craft of qualitative research interviewing (2nd ed.). Thousand Oaks, CA, US: Sage Publications, Inc.

Lancaster, B. M. (2005). Assessment and treatment of autism. Indian Journal of Pediatrics, 72(1), 45-52. doi: https://doi.org/10.1007/BF02760580

Lee, A. M. I. (2019). 10 key procedural safeguards in IDEA. Retrieved from www.understood.org/en/school-learning/your-childs-rights/basics-about-chils-right/10-keyprocedural-safeguards-in-idea

Levy, S. E., Mandell, D. S., \& Schultz, R. T. (2009). Autism. Lancet, 374, 1627-1635. doi: 10.1016/s0140-6736(09)61376-3

McDougle, C. J., Stigler, K. A., Erickson, C. A., \& Posey, D. J. (2006). Pharmacology of autism. Clinical Neuroscience Research, 6, 179-188. doi: 10.1016/j.cnr.2006.06.012

Mire, S. S., Raff, N. S., Brewton, C. M., \& Goin-Kochel, R. P. (2015). Age-related trends in treatment use for children with autism spectrum disorder. Research in Autism Spectrum Disorders 15, 29-41. doi: http://dx.doi.org/10.1016/j.rasd.2015.03.001

Myers, S. M., \& Plauche Johnson, C. (2007). Management of children with autism spectrum disorders. American Academy of Pediatrics, 120(5), 1162-1182. doi: 10.1542/peds.2007-2362

National Institutes of Health. (2015). Complementary and alternative medicine. Retrieved from https://www.cancer.gov/about-cancer/treatment/cam

Palermo, M. T., \& Curatolo, P. (2004). Pharmacological treatment of autism. Journal of Child Neurology, 19(3), 155-164.

Pituch, K. A., Green, V. A. Didden, R., Lang, R., O’Reilly, M. F., Lancioni, G. E., \& Sigafoos, J. 
(2011). Parent reported treatment priorities for children with autism spectrum disorders.

Research in Autism Spectrum Disorders, 5, 135-143. doi: 10.1016/j.rasd.2010.03.003

Polenick, C. A., \& Flora, S. R. (2012). Sensory intergration and autism: Science or pseudoscience? Skeptic, 17(2). 28

Rogers, S. J. \& Vismara, L. A. (2008). Evidence-based comprehensive treatments for early autism. Journal of Clinical Child and Adolescent Psychology, 37(1), 8-38. doi: https://doi.org/10/1080/15374410701817808

Sandelowski, M., Voils, C. I., \& Knafl, G. (2009). On quantitizing. Journal of Mixed Methods Research, 3(3), 208-222.

Sheinkopf, S. J., \& Siegel, B. (1998). Home-based behavioral treatment of young children with autism. Journal of Autism and Developmental Disorders, 28(1), 15-23.

Taylor, J. L., McPheeters, M. L., Sathe, N. A., Dove, D., Veenstra-VanderWeele, J., \& Warren, Z. (2012). A systematic review of vocational treatments for young adults with autism spectrum disorders. Pediatrics, 130(3). 531-538. doi: 10.142/peds.2012-0682

Tomchek, S., LaVesser, P., \& Watling, R. (2010). The scope of occupational therapy services for individuals with an autism spectrum disorder across the life course. The American Journal of Occupational Therapy, 64, 125-136.

Truven Health Analytics, (2018). Risperdone. Retrieved from https://www.ncbi.nlm.nih.gov/pubmedhealth/PMHT0012012/?report=details\#side_effects

Watling, R., Deitz, J., Kanny, E.M., \& McLaughlin, J.F. (1999). Current practice of occupational therapy for children with autism. The American Journal of Occupational Therapy, 53(5), 498-505. doi: 10.5014/ajot.53.5.498

Weaver, L. L. (2015). Effectiveness of work, activities of daily living, education, and sleep 
treatments for people with autism spectrum disorder: A systematic review. The American Journal of Occupational Therapy, 69(5), 6905180020.

http://dx.doi.org/10.5014/ajot.2015.017962

Wong, H. H. L., \& Smith, R. G. (2006). Patterns of complementary and alternative medical therapy use in children diagnosed with autism spectrum disorder. Journal of Autism and Developmental Disorders, 36, 901-909. doi: 10.1007/s10803-006-0131-0 


\section{Appendix A}

1. How would you describe a typical day with your child?

2. How much help does your child need during the day? With what? How do you help him/her?

3. What are your top three goals for your child?

4. Please describe reasons for selecting treatments for your child with autism.

5. Please identify some reasons for stopping treatments?

6. What changes did you see in your child from the treatments used that you would identify as being the most significant? Did you experience any negative outcomes?

7. Have you as a caregiver (or other caregivers) for your child with autism utilized services to assist you with coping or management of your child?

8. Do you want to add anything else about autism treatments and services for your child? 


\section{Appendix B}

\section{Category Treatments}

Medical Vagal nerve stimulation, psychiatrist, psychologist, neurologist, intravenous

immunoglobulin (IVIG), transfer factor pentoxifyllinbasic fibroblast growth

factor (BCGF), medication intravenous chelation, chelation pills,

detoxification

Dietary Dietician, nutritionist, gluten free diet, casein free diet, Feingold diet, soy

free diet, dye free diet, yeast free diet, low carbohydrate or carb free diet, artificial sweetener free diet, vitamins/ supplements

Therapy Occupational therapy; physical therapy; speech and language therapy; early

intervention; electronic speaking device; art therapy; music therapy; play

therapy; dance therapy; sensory integration; counseling; sounds based

treatments such as auditory training (AIT), Therapeutic Listening, Tomatis

program, or Listening program; interactive metronome; animal assisted

therapy with animals like a dog, cats, bird, rat; therapeutic riding;

hippotherapy; manual therapy; sign language; social pragmatics approach;

weighted vest or blanket; multisensory environments such as Snoezelen;

holding therapy; assistive technology; integrated movement therapy; Bolles

sensory learning; rapid prompting method; facilitated communication;

exercise

CAM Relaxation techniques such as deep breathing, yoga, acupuncture, Reiki, chiropractor, fortune teller/ palm reader, Buddhist monk interaction, hyperbaric oxygen chamber, craniosacral manipulation, massage, qigong, 
transcranial stimulation, aromatherapy, Irlen lenses, Watsu, rolfing, marijuana, cannabinol oil (CBD/ hemp oil)

Community Advocacy support, religious or spiritual support, autism support group, respite, job coaching, supported employment, transition services, sheltered workshop

Behavioral Pivotal response training, psychotherapy, integrated behavioral therapy (IBT), applies behavioral analysis (ABA), positive behavioral support, positive reinforcement, negative reinforcement, discrete trial training, cognitive behavioral treatment, neurofeedback, early intensive behavioral treatment (EIBT), DIR floortime, antecedent-based intervention, cognitive behavioral intervention (CBI), behavioral specialist consultant (BSC), therapeutic staff support (TSS), cognitive enhancement therapy (CET, enriched supportive therapy (EST)

Educational Option program; use of a resource room in school; SCERTS- social, communication, emotional regulation transactional support; modeling' TEACCH method- treatment and education of autistic and related communication handicapped children; Denver model; social skills training; social interaction groups; Social Stories; picture exchange communication system (PECS); special education classroom; regular education classroom/ inclusive classroom/ mainstreamed; autism support classroom; behavior support classroom; learning support classroom; STAR program- strategies for teaching based on autism research; LEAP program preschool; Child Alert preschool; Head Start preschool; Pre-K program; Son-Rise program; 
Montessori school; Individualized Family Service Plan (IFSP);

Individualized Education Program (IEP); 1 on 1 aide in school; support services for school transportation; after school services; weekend school support services; visual schedule; Gentle teaching; Learning experiences and alternative program for preschoolers and parents; functional communication training, school-based occupational therapy; school-based speech therapy; school-based physical therapy; private special education school; life skills classroom; extended school year/ summer school; partial hospitalization program; responsive teaching curriculum (RT) 